Original Article (short paper)

\title{
The use of surface electromyography to assess transfemoral amputees: methodological and functional perspective
}

\author{
Rafaella C. Silva ${ }^{1,2}$, Thanyze A. V. Zoccoli ${ }^{1,2}$, Vera R.F.S. Marães ${ }^{1,2}$ \\ ${ }^{1}$ Universidade de Brasilia, Departamento de Engenharia Biomédica, Brasília, DF, Brasil; \\ ${ }^{2}$ Universidade de Brasília, UnB, Departamento de Engenharia Biomédica, Grupo de Pesquisa \\ em Saúde e Tecnologias de Amputados Transfemorais, Brasilia, DF, Brasil
}

\begin{abstract}
Aim: Surface electromyography (sEMG) has been established as a safe non-invasive method to investigate neuromuscular function. However, the use of this instrument to assess lower limbs of transfemoral amputees still presents a lack of standardization in its methods of signal acquisition and processing. The aim of this study was to review the current state of sEMG utilization to assess transfemoral amputees, the procedures adopted for the acquisition and the functional findings. Methods: This is a literature review. Five electronic databases were searched to find the studies: All relevant information of each study was extracted and registered. Methodological quality was evaluated using a customized checklist. Results: Eight studies followed the inclusion criteria and were included in this paper. Four studies did not reach more than $80 \%$ of the quality checklist, few studies fully described the methodology applied. The muscles assessed were similar in all studies, electrodes placement was determined by different criteria. Conclusion: This paper demonstrates that a few studies have used this method to assess this population and the main variable aspect is concerned to the placement of the electrodes. More researches are needed to better understand the neuromuscular behavior of amputees by using sEMG and assist future researches to develop more reproducible and reliable studies.
\end{abstract}

Keywords: electromyography, literature review, transfemoral amputation, transected muscles, quality assessment.

\section{Introduction}

Surface electromyography (sEMG) consists of a non-invasive method which allows the detection of electric potentials of voluntary muscles, and it has established as an important method of investigation of the neuromuscular system and behavior $1^{2}$.

Transfemoral amputee population can be benefited by surface electromyography researches through understanding the modifications that occur after amputation and also assisting the development of locomotion devices. Studies have shown that the electromyographic signal as a neural source for a prosthesis is more informative than the cinematographic signal ${ }^{3}$. However, before the development and prescription of prosthetics, it is necessary to understand muscle condition after amputation and investigate its effects on life activity ${ }^{4-6}$. Although it is fundamental, there is a lack of research investigating muscle function after amputation ${ }^{6-8}$. The evaluation of the residual musculature provides valuable information about the adaptations that occur; however, its form of acquisition and reproducibility can be compromised by the absence of studies.

Knowing that the acquisition of the electromyographic signal can be affected by several factors related to the methodological planning or the individual characteristics, some recommendations to use this method were established to optimize biological signal acquisition, aiming at a reliable measurement system and consequent analysis and interpretation with safety ${ }^{1,2,9}$. In order for the acquired signal to present sufficient quality for its use, the acquisition must follow a well-defined and preestablished route.

When assessing amputees some gaps persist, such as the correct positioning of electrodes on the amputated limb and the use of prostheses during the evaluation, characterizing important limiting factors for the acquisition and processing of this signal.

Considering this context, this review intends to collect information about the neuromuscular evaluation of transfemoral amputees through the use of surface electromyography to verify what methodological aspects were used by researches to acquire the signal, what are the common procedures in use in this field by gathering such records to assist future researches of the area. This review aims to gather information about (a) the quality of studies which used sEMG to assess TA; (b) the purposes of its use; (c) which methodological recommendations were used; (d) the main outcomes and limitations found by the researches.

\section{Material and methods}

The present study is characterized as a bibliographical review of the literature, which followed methodological criteria for the search strategy, inclusion and exclusion criteria for the analysis of the studies. This study was approved by the Ethics Committee of The Faculty of Health Sciences of University of Brasília (CAE: 38386714800000030 ). The focus of this review is to identify the studies that used surface electromyography to 
assess the musculature of transfemoral amputees. It contains an overview of the use of electromyogram instrument and the methodological aspects adopted in each study.

The databases were selected according to relevance with the topic being investigated: Medline $\left({ }^{\circ}\right.$ Copyright NCBI), BVS (Biblioteca Virtual de Saúde, ${ }^{\circ}$ BIREME), Scopus, ScienceDirect ( ${ }^{\circ}$ Copyright, Elsevier BV) and IEEE Xplore ( ${ }^{\circ}$ Copyright, IEEE). The search strategy that was adopted was based on the terms described in table 1 that were combined logically, according to the requirements of each database.

Table 1. Search terms adopted in the literature search

Electromyography (surface electromyography OR non-invasive electromyography)

AND

Transfemoral amputee OR transfemoral amputation OR lower limb amputee OR lower limb amputation OR above knee amputation OR above knee amputee

After searching the databases, 1126 documents were retrieved. The results were imported into the EndNote software (X7, Thomson Reuters, USA) and the duplicate studies were removed. The remaining articles were evaluated based on their titles and abstracts, without language restriction or date of publication. Two independent investigators reviewed titles and abstracts. The screening resulted in a total of 49 potentially relevant studies to be analyzed.

After full-text reading, the studies included in the review were evaluated by using a record prepared by the authors to extract information of interest related to study population (transfemoral amputees), evaluation method used (surface electromyography). Data were recorded regarding the characterization of the sample, description of the electromyography instrument used, as well as the methodology applied for its use and evaluation (Table 2). All data of interest were extracted from the selected studies and cases of omission of information were also flagged.

Table 2. Aspects of interest evaluated in studies

a. Manuscript: author, journal, year of publication.

b. Sample: demographic and anthropometric characteristics of the amputees and their control group, when present.

c. Instrumentation: brand and specifications of the acquisition device, type and positioning of electrodes, processing and signal analysis.

d. Obtained results and observations of the researches regarding the execution of the research.

This review focuses on investigating the use of electromyography in transfemoral amputees and studies that contained nonhuman simulations or only concepts and theories were excluded.

A checklist was developed based on an existing assess lists ${ }^{10,11}$, the elements based on the relevant information to our study were modified with a focus on the description made of each study about their methodological design. (Table 3). The checklist was composed of 13 items, which were classified in 0 (not described), 1 (poorly described) and 2 (fully described). The authors established good quality for studies that present $\geq 70 \%$ of the maximal score, medium when presents $\geq 50 \%$ and low quality with $\leq 50 \%$.

Table 3. Quality assessment checklist

\begin{tabular}{ll}
\hline 1. The research aims were clearly stated. & $0-1-2$ \\
2. The study design was clearly described. & $0-1-2$ \\
3. The study population was adequately described. & $0-1-2$ \\
4. The inclusion and exclusion criteria were described. & $0-1-2$ \\
5. The assessment method was clearly described. & $0-1-2$ \\
6. The EMG device was clearly described. & $0-1-2$ \\
7. The sensors were clearly described. & $0-1-2$ \\
8. The sensor location criteria were clearly described. & $0-1-2$ \\
9. The skin preparation before acquisition was clearly & $0-1-2$ \\
10. The data processing was clearly described. & $0-1-2$ \\
11. The EMG data were clearly described. & $0-1-2$ \\
12. The outcomes were clearly described. & $0-1-2$ \\
13. The limitations of the study were clearly described. & $0-1-2$ \\
\hline
\end{tabular}

\section{Results and Discussion}

A total of 1180 studies were found, after eliminating all duplicates, 384 studies were left. After the reading of abstracts and titles, 335 were excluded. Of the 49 studies selected for full-text reading, eight studies were included in this review. The selection process is described in fig. 1 .

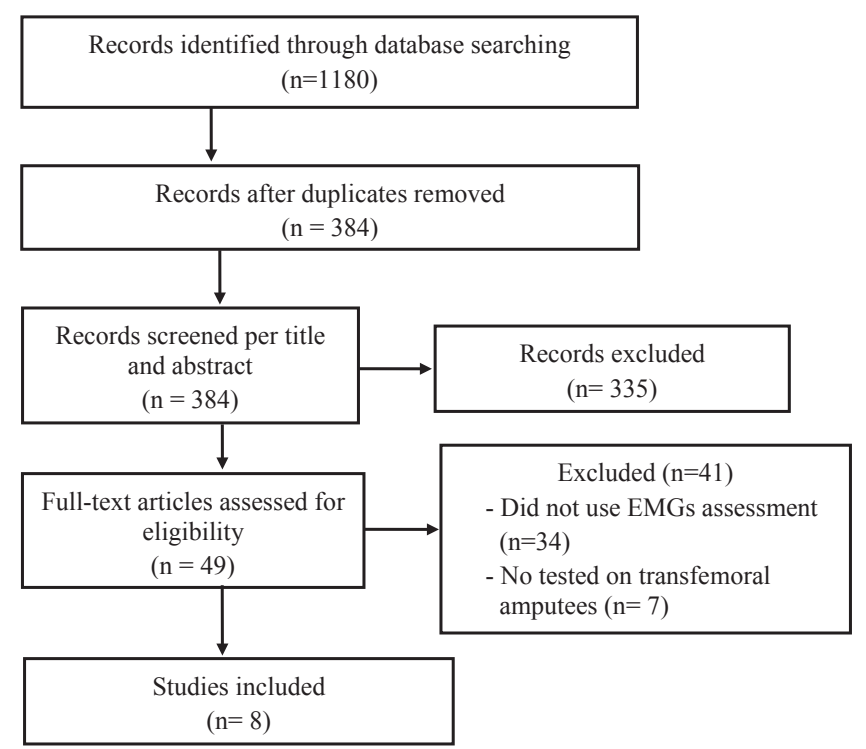

Figure 1. Flowchart summarizing the review process.

An overview of all included studies was shown in table 4 . The use of a customized checklist allows the evaluation of the methodological quality to be more focused to the aspects of interest of this review, allowing the evaluation of the quality of the study according to the most relevant information. The methodological quality of the articles measured by the checklist presented average percentage values of $80 \%$, indicated high quality by the majority of the studies. The 
main points not observed in the articles were: study design, skin preparation before the acquisition and description of the limitations found.

Five studies fully described the inclusion criteria of its participants. Although most of the studies describe the instrumentation used and the method of signal acquisition, only two studies clearly described how skin preparation was done, a procedure strongly recommended for the adequate acquisition of the EMG signal ${ }^{1}$. The limitations encountered in the development of the study were clearly described in four studies.

The selected studies had as main objectives: to investigate the electromyographic patterns of amputees using osteo fixed prostheses ${ }^{7,8}$, to verify possible changes and adaptations in muscle activation after amputation and prosthetization process ${ }^{5,6,12,13}$, to evaluate the kinematic and electromyographic variation of the muscles during gait ${ }^{4,5,13}$, to describe the behavior of ground reaction force and electromyographic activation ${ }^{14}$.

In addition to transfemoral amputees, one study also included participants with knee disarticulation ${ }^{8}$. Two studies did not include a control group for comparison ${ }^{13,14}$. Due to the characteristics of the sample studied, samples size was small, not only in the transfemoral group (min. 3 and max. 11) but also in the control group (min. 3 and max. 10). Most of the amputee subjects included were men and the aetiology most related was traumatic. Not all studies have reported on the aetiology of amputations.

Only one study reported having recruited participants with vascular amputations ${ }^{12}$. The majority of studies excluded the volunteers who had this cause of amputation from the sample. This choice may be justified by the low rate of prosthetized amputees by vascular cause. This aetiology is directly related to the process of prosthetization, rehabilitation and return to functional activities ${ }^{6,15}$.

All studies, except for Cerqueira, Yamaguti, Mochizuki, Amadio, Serrão ${ }^{14}$, and Nakamura, Hahn ${ }^{13}$ made comparisons with a control group that was composed of healthy individuals without amputation. However, it can be seen that amputated samples, for the most part, present great variation in the general characteristics, especially concerning to age, whereas the groups of controls have more homogenous characteristics.

Table 4. General characteristics of selected studies rated by year of publication.

\begin{tabular}{|c|c|c|c|c|c|c|}
\hline $1^{\circ}$ Author (year) & Participants & Muscles & Instrumentation & Processing & Analysis & Quality score \\
\hline Nakamura BH (2016) & 5 TFA & $\begin{array}{c}\mathrm{RF}, \mathrm{VL}, \mathrm{BF}, \mathrm{GMe}, \\
\mathrm{TA}, \mathrm{GC},\end{array}$ & $\begin{array}{l}\text { Noraxon Telemyo } \\
\text { DTS; (Scottsdale) }\end{array}$ & $\begin{array}{c}\text { SF: } 1500 \mathrm{~Hz} \\
\text { BPF: } 3-500 \mathrm{~Hz} \\
\text { LPF: } 6 \mathrm{~Hz}\end{array}$ & Normalization & $69 \%$ \\
\hline Pantall A. (2013) & $\begin{array}{l}5 \mathrm{TFA} \\
10 \mathrm{CG}\end{array}$ & $\begin{array}{c}\mathrm{GMa}, \mathrm{GMe}, \mathrm{RF}, \mathrm{BF}, \\
\mathrm{AM}\end{array}$ & $\begin{array}{l}\text { DataLINK DLK800 } \\
\text { (Biometrics Ltd., } \\
\text { UK) }\end{array}$ & SF: $1000 \mathrm{~Hz}$ & $\begin{array}{l}\text { Normalization } \\
\text { Moving average } \\
\text { value of EMGs }\end{array}$ & $84 \%$ \\
\hline Wentink EC. (2013) & $\begin{array}{l}3 \mathrm{TFA} \\
3 \mathrm{KD} \\
5 \mathrm{CG}\end{array}$ & $\begin{array}{c}\text { GMa, GMe, TF, RF, } \\
\text { VL, BF, ST, AM, TA, } \\
\text { GC, SO }\end{array}$ & $\begin{array}{l}\text { Porti-system } \\
\text { (TMSi, Oldenzaal, } \\
\text { Netherlands) }\end{array}$ & $\begin{array}{l}\text { HPF: } 10 \mathrm{~Hz} \\
\text { LPF: } 500 \mathrm{~Hz} \\
\text { SF: } 2040 \mathrm{~Hz}\end{array}$ & $\begin{array}{l}\text { Rectification } \\
\text { EMGs integral } \\
\text { (tON e tOFF) }\end{array}$ & $84 \%$ \\
\hline Cerqueira ASO. (2013) & 3 TFA & VL, BF, TA, GC & $\begin{array}{l}\text { Bagnoli-8 (Delsys, } \\
\text { Boston) } 12 \text { bits }\end{array}$ & $\begin{array}{c}\text { SF: } 1000 \mathrm{~Hz} \\
\text { BPF: } 20-450 \mathrm{HZ}\end{array}$ & $\begin{array}{l}\text { Normalization } \\
\text { tON e tOFF }\end{array}$ & $92 \%$ \\
\hline Pantall A. (2011) & $\begin{array}{l}5 \mathrm{TFA} \\
10 \mathrm{CG}\end{array}$ & $\begin{array}{c}\mathrm{GMa}, \mathrm{GMe}, \mathrm{RF}, \mathrm{BF}, \\
\mathrm{AM}\end{array}$ & $\begin{array}{l}\text { DataLINK DLK800 } \\
\text { (Biometrics Ltd., } \\
\text { UK) }\end{array}$ & $\begin{array}{l}\text { LPF: } 460 \mathrm{~Hz} \\
\mathrm{HPF}: 20 \mathrm{~Hz}\end{array}$ & $\begin{array}{c}\text { Mean rectified } \\
\text { wave } \\
\text { Median Frequency }\end{array}$ & $84 \%$ \\
\hline Bae TS. (2009) & $\begin{array}{l}8 \mathrm{TFA} \\
10 \mathrm{CG}\end{array}$ & $\begin{array}{l}\text { GMa, VM, VL, RF, } \\
\text { BF, ST, SO, GC, TA }\end{array}$ & $\begin{array}{c}\text { Myosystem } \\
\text { (Noraxon System, } \\
\text { Scottsdale) }\end{array}$ & $\begin{array}{c}\text { BPF: } 30-400 \mathrm{~Hz} \\
\text { BSF: } 60 \mathrm{~Hz} \\
\text { SF: } 1024 \mathrm{~Hz}\end{array}$ & $\begin{array}{c}\text { Normalization } \\
\text { Root Mean Square }\end{array}$ & $69 \%$ \\
\hline Bae (2007) & $\begin{array}{l}8 \mathrm{TFA} \\
10 \mathrm{CG}\end{array}$ & $\begin{array}{l}\text { GMa, VM, VL, RF, } \\
\text { BF, ST, SO, GC, TA }\end{array}$ & $\begin{array}{l}\text { Myosystem 1400, } \\
\text { (Noraxon system } \\
\text { Inc., AZ, USA) }\end{array}$ & $\begin{array}{c}\text { SF: } 1024 \mathrm{~Hz} \\
\text { BPF: } 30-400 \mathrm{~Hz} \\
\text { BSF: } 60 \mathrm{~Hz}\end{array}$ & $\begin{array}{c}\text { Normalization } \\
\text { Root Mean Square }\end{array}$ & $74 \%$ \\
\hline Jaegers (1996) & $\begin{array}{l}11 \mathrm{TFA} \\
3 \mathrm{CG}\end{array}$ & $\begin{array}{c}\text { GMa, GMe, TF, RF, } \\
\text { VL, BF, ST, AD, TA, } \\
\text { GC, SO, SA, SM }\end{array}$ & $\begin{array}{l}\text { SPA K-Lab } \\
\text { (Enschede, The } \\
\text { Netherlands) }\end{array}$ & - & Rectification & $77 \%$ \\
\hline
\end{tabular}

AD: adductors muscles, AM: adductor magnus, BF: biceps femoris, BPF: band pass frequency, BSF: band stop filter, CG: control group, GC: gastrocnemius, GMa: gluteus maximus, GMe: gluteus medius, HPF: high pass frequency, KD: knee disarticulation, LPF: low pass frequency, RF: rectus femoris, SA: sartorius, SF: sampling frequency, SM: semimembranosus, SO: soleus, ST: semitendinosis, TA: tibialis anterior, TFA: transfemoral amputee, TF: tensor fasciae latae, TFA: transfemoral amputees, VL: vastus lateralis, VM: vastus medialis.

Although limb amputation is not uncommon, there are some limitations in bringing together similar individuals ${ }^{5,14}$. This observation may be related to the difficulty of recruitment of transfemoral amputees and to the specificities of this population, such as causes and time of amputation, adequate protection, functional level and stabilization in the individual's mass and residual stump volume ${ }^{4,12}$.

After transfemoral amputation, with loss of knee joint, individuals suffer damage concerning to bone structure, balance and posture, and metabolic demand ${ }^{16,17}$. It is essential to assess 
the remaining musculature responsible for gait and propulsion, especially for rehabilitation and adequate prosthetization. This changes in muscles morphology have consequences for function and activity as well as influences the functionality and autonomy of this subjects ${ }^{6,18.19}$.

Due to the characteristics of the transfemoral amputation and the adaptations that it causes, the muscles analyzed by the studies were similar. All studies selected muscle groups of the thigh, six of them also included hip musculature ${ }^{4-8,12}$ and four of them included leg muscles in the contralateral limb $b^{4,5,12,14}$. Figure 2 shows the frequency of evaluated muscles in studies.

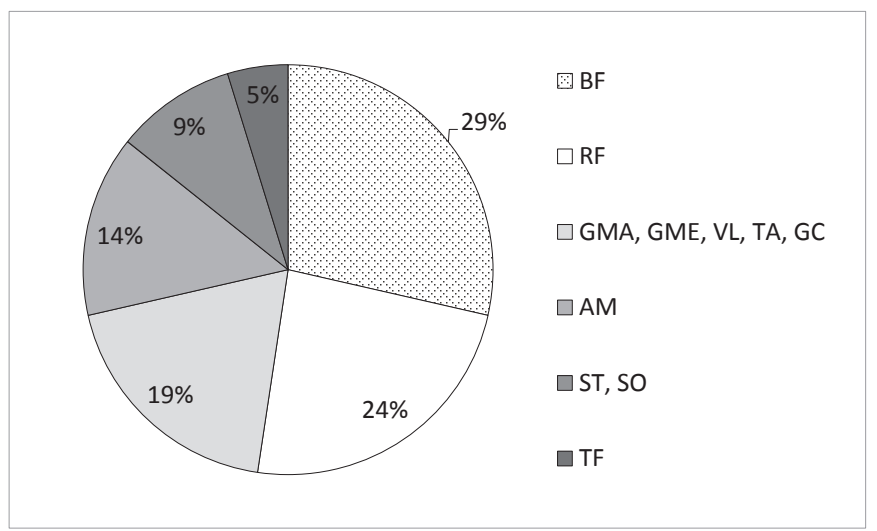

Figure 2. Relative frequency of muscles studied in included studies (AM: adductor magnus, BF: biceps femoris, GC: gastrocnemius, GMA: gluteus maximus, GME: gluteus medius, RF: rectus femoris, SO: soleus, ST: semitendinosis, TA: tibialis anterior, TF: tensor fasciae latae, VL: vastus lateralis).

Together with the EMGs evaluation, kinematic gait analysis was observed in most studies. This may be associated with its importance when investigating the consequences of amputation and to assess whether prosthetization process was satisfactory and the level of amputee's independence.

Different techniques to determine electrode placement were adopted in the articles, three studies made use of SENIAM standards for preserved musculature, combined with different techniques for amputated musculature, including palpation associated with muscle function test ${ }^{7}$ and simultaneous visualization of the electromyographic signal during contraction ${ }^{8,12}$. Four studies determined the positioning of electrodes in the muscle belly ${ }^{4-6,13}$ and another study used the verification of the motor point by employing electrical stimulation and positioned the electrodes $1 \mathrm{~cm}$ away from the motor point ${ }^{14}$. Only one study reported using an experienced physiotherapist to select electrode placement ${ }^{12}$.

For the acquisition of the electromyographic signal, the studies used different instruments, but all with sufficient technical requirements for an adequate acquisition, as recommended in the literature ${ }^{1,2}$. Both the electromyographic signal processing adopted by the studies and the selected indices for its registry corroborate the values used in studies of other populations, which may facilitate the inter-subject comparison in different studies.

All studies described an overview of specifications of the electromyographic acquisition device used (Table 4), only six studies have specified the type of electrode used for the acquisition $^{4-6,12-14}$. All studies made use of the EMG device simultaneously to other assessment instruments.

Regarding the processing of the electromyographic data, in all of the studies, data from the sensors were collected, transmitted to computers and stored for subsequent processing. Butterworth, Bessel, and Cut-off filters were adopted in most of the studies. Only three studies ${ }^{4,5,7}$ did not report the type of filter used.

The calculation and the result of the data were executed differently in each study, they were: calculation of the moving average value and normalization from the amplitude of greater value recorded during an acquisition ${ }^{5,7}$. Rectification ${ }^{6}$ and calculation of sEMG integral ${ }^{10}$, mean of rectified wave and median frequency ${ }^{6}$, normalization from the CVM and $\mathrm{RMS}^{4,5}$, normalization from the peak ${ }^{13}$, rectified complete wave calculation, normalization concerning to its mean value ${ }^{14}$.

The results found corroborate with previously determined hypotheses that differences between the electromyographic values of the two groups studied would be observed ${ }^{4,-8,12}$ and among individuals with different time of use of the prosthesis ${ }^{14}$.

Regarding the activity performed to acquire the electromyographic signal, three of the selected studies evaluated the electromyographic activity only during gait ${ }^{6,7,10}$, three studies added the task of climbing stairs ${ }^{4,5,13}$. The study by Cerqueira, Yamaguti, Mochizuki, Amadio, Serrão ${ }^{14}$ associated gait and steps in a force platform, while the remaining study ${ }^{8}$ evaluated electromyographic activity only during maximal isometric contractions.

The main findings during gait were the observation of cyclic patterns in the electromyographic activation profile, not only in non-amputated individuals but also in amputees using osteofixed prostheses, different from those found in individuals using conventional prostheses ${ }^{7}$.

Of the studies that evaluated the distal musculature of the non-amputated limb, Bae, Choi, Hong and Mun ${ }^{5,6}$ found higher values of hip muscles activation in the amputee group during gait, this can be associated to a compensative mechanism to assist the impaired contralateral quadriceps activation. The control groups presented higher values of the electromyographic indices than the groups of amputees studied in four studies ${ }^{4-8,10}$, amputees presented longer periods of activation and greater variations, which can be justified by the kinematic changes that vary more ${ }^{12,13}$.

The study by Cerqueira, Yamaguti, Mochizuki, Amadio, Serrão ${ }^{14}$ which only evaluated amputees with different times of use of prosthesis verified that the muscular activations varied among the participants. This suggests that there are different motor strategies to adapt their gait, these differences of abilities may be responsible for the differences in gait pattern. The gait performance and muscle activation pattern closer to the 'typical' pattern was performed by the participant with longer prosthesis use.

Concerning the activity of muscle groups of the intact limb during gait, greater activations were observed in vastus lateralis, tensor fasciae latae in amputees muscles, this strategy is very observed in lower limb amputees, which the lack of propulsion of the affected limb ends up requiring more activity of the intact $\operatorname{limb}^{5,14}$. During the descent of the stairs, the control group presented lower muscle activation values in all the musculatures 
evaluated, whereas in the ascending of steps ${ }^{4}$, all muscles of the amputated group, except knee flexors, presented higher EMG values when compared to group control. This fact may be associated with increased hip and residual thigh muscles effort in the displacement of the prosthetic limb to the step above, as well as the attempt to compensate the intact limb in not unloading the weight in the prosthetic limb $b^{4,5}$.

In one study ${ }^{8}$ none of the amputees was able to maintain constant strength in isometric contraction for 5 seconds. In addition, the amputee group presented higher median frequency values in the Gmed and AM muscles, an index commonly related to the occurrence of muscle fatigue ${ }^{1,2}$.

Regarding the methodological difficulties encountered during the signal acquisition phase, the positioning of electrodes and their insertion into conventional prostheses are the main obstacles reported in the studies. They are indicated as a possible cause of the high variability of acquired signals ${ }^{7,13}$, an increase of movement artifacts, compromising signal reproducibility ${ }^{12}$ and performance of the tasks ${ }^{4,5}$.

Studies have also found high variability of sEMG and this variability can be explained by delays in the transmission of muscle force to the bone, reduction of receptors and feedback, as well as the activation of synergists during contraction ${ }^{8}$. Another possible explanation for the high variability of EMG values relates to new motor strategies to adapt and stabilize movement after amputation. These differences in abilities may be responsible for the differences observed not only in electromyographic indices, but also observed in the different walking patterns ${ }^{13,14}$.

It is known that the acquisition of surface electromyography signal can be affected by several extrinsic and intrinsic factors. In this way, the proper positioning of the electrodes facilitates and improves the signal quality to be collected. Consideration should be given to the location, type and direction of muscle fibres under study, skin integrity and skin-electrode interface, as well as the distance between the skin surface and the muscle fibres and the inter-electrode distance $\mathrm{e}^{9,20}$.

However, the existing protocols to guide the positioning of the electrodes are based on individuals without physical deficiency, with musculoskeletal integrity, and there are no specific protocols for people with limb amputation. Thus, one of the great challenges in the collection of EMG signals in amputees is to find the best way to position the electrodes, since the physical loss of the limb can lead to changes in strength, length and muscle mass, sense and number of muscle fibres and function muscular ${ }^{16,17,21}$.

These changes and difficulties justify the combination of positioning techniques adopted by the studies included in this review, however, there is no consensus in the literature of which technique or which combination is most adequate to guide the positioning of the electrodes in the amputated stump. Therefore, reliable evaluation of EMG signals from the residual limbs of transfemoral amputees still presents a great challenge ${ }^{5,22}$.

Because it is a non-invasive and easily accessible method, the use of EMGs allows its application in various forms and purposes. However, the determination of its collection methodology is still a point of great importance and efforts must be made to standardize the method. Facilitating the comparison between different studies carried out by different researches.

This review aimed to examine the existing literature and to identify the current state of surface electromyography utilization for the assessment of transfemoral amputees. There is a lack of research on muscle function after amputation and when studied, the information presented in the methods section was limited. The main outcomes were that the muscles assessed were similar while methods for electrode placement differed across studies. The small number of studies found in the literature shows the lack of standardization of its use in this population and may be associated to the difficulties existing from the recruitment of the sample until the moment of data acquisition.

Assuming that the lack of previous evaluation can lead to impairment in the execution of more advanced studies in the area of assistive technologies, it is necessary that new researches arise with the objective not only of investigating the muscular function of transfemoral amputees but first helping in the adoption of patterns of acquisition and improvement quality of these studies.

\section{References}

1. De Luca CJ. The use of electromyography in biomechanics. J Appl Biomech. 1997, (13): 135-163. DOI: 10.1123/jab.13.2.135

2. Merletti R. Standards for reporting EMG data. Journal of Electromyography and Kinesiology. 1997; 7(2):I- II.

3. Zhang F, Huang H. Source selection for real-time user intent recognition toward volitional control of artificial legs. IEE J Biomed Health Inform. 2013; 17(5):907-14. DOI:10.1109/ JBHI.2012.2236563.

4. Bae TS, Choi K, Mun M. Level walking and stair climbing gait in above-knee amputees. Med Eng Technol. 2009;33(2):130-5. DOI: 10.1080/03091900701404043.

5. Bae TS, Choi K, Hong D, Mun M. Dynamic analysis of above-knee amputee gait. Clinical Biomechanics. 2007; 22:557-566. DOI: 10.1016/j.clinbiomech.2006.12.009.

6. Jaegers SMHJ, Arendzen JH, Jongh HJ. An electromyographic study of the hip muscles of transfemoral amputees in walking. Clinical Orthopaedics and Related Research. 1996; 328:119-128.

7. Pantall A, Ewins D. Muscle activity during stance phase of walking: comparison of males with transfemoral amputation with osseointegrated fixations to nondisabled male volunteers. J Rehabil Res Dev. 2013; 50(4):499-514. DOI: 10.1682/JRRD.2011.10.0204.

8. Pantall A, Durham S, Ewins D. Surface electromyography activity of five residual limb muscles recorded during isometric contraction in transfemoral amputees with osseointegrated prostheses. Clinical Biomechanics. 2011; 26(7):760-65. DOI: 10.1016/j. clinbiomech.2011.03.008.

9. Hermens HJ, Freriks B, Merletti R, Stegeman, Blok J, Rau G, Disselhorst-Klug C et al. European recommendations for surface 304 electromyography SENIAM project. 2000. Available in: http:// seniam.org/.

10. Papi E, Koh WS, McGregor AH. Wearable technology for spine movement assessment: A systematic review, Journal of Biomechanics. 2017; 7(64):186-197. DOI:10.1016/j.jbiomech.2017.09.037. 
11. Martens J, Figueiredo P, Daly D. Electromyography in the four competitive swimming strokes: A systematic review. J Electromyogr Kinesiol. 2014; 25(2):237-291. DOI:10.1016/j. jelekin.2014.12.003.

12. Wentink EC, Prinsen EC, Rietman JS, Veltink PH.. Comparison of muscle activity patterns of transfemoral amputees and control subjects during walking. J Neuroeng Rehabil. 2013; 2(10):87. DOI: $10.1186 / 1743-0003-10-87$.

13. Nakamura BH, Hahn M.E. Myoelectric activation differences in transfemoral amputees during locomotor state transitions. Biomedical Engineering: Applications, Basis and Communications. 2016 28(5):1650041. DOI: 10.4015/S1016237216500411.

14. Cerqueira ASO, Yamaguti EY, Mochizuki L. Amadio AC, Serrão JC. Ground reaction force and electromyographyc activity of transfemoral amputee gait: a case series. Rev Bras Cineantropom Desempenho Hum. 2013; 15(1):16-26. DOI: 10.5007/1980-0037.2013v15n1p16.

15. Deans S, Burns D, McGarry A, Murray K, Mutrie N. Motivations and barriers to prosthesis users participation in physical activity, exercise and sport: a review of the literature. Prosthet Orthot Int. 2012; 36(3):260-269. DOI: 10.1177/0309364612437905.

16. Gjovaag T, Starholm IM, Mirtaheri P, Hegge FW, Skjetne K. Assessment of aerobic capacity and walking economy of unilateral transfemoral amputees. Prosthetics and Orthotics International. 2014;38(2): 140-147. DOI:10.1177/0309364613490444.

17. Velzen JM van, Bennekom CA van, Polomski W, Slootman JR, van der Woude LH, Houdijk H. Physical capacity and walking ability after lower limb amputation: a systematic review. Clinical Rehabilitation. 2006; 20(11):999-1016. DOI:10.1177/0269215506070700.

18. Huang H, Zhang F, Hargrove LJ, Dou Z, Roggers DR, Englehart KB. Continuous Locomotion-Mode Identification for Prosthetic Legs Based on Neuromuscular-Mechanical Fusion. IEEE Trans Biomed Eng. 2011; 58(10): 2867-2875. DOI:10.1109/ TBME.2011.2161671.
19. Huang, S \& Ferris, DP. Muscle activation patterns during walking from transtibial amputees recorded within the residual limb-prosthetic interface. Journal of NeuroEngineering and Rehabilitation. 2012; 9:55. DOI: 10.1186/1743-0003-9-55.

20. Hermens HJ, Freriks B, Disselhorts-Klug C, Rau C. Development of recommendations for SEMG sensors and sensor placement procedures. Journal of Electromyography and Kinesiology. 2000;10(5):361-74. DOI: 10.1016/S1050-6411(00)00027-4.

21. Marães VRFS, Cruz BOAM, Moreira JA, Sampaio TF, Almeida CC, Garcia PA. Avaliação do quadril de amputados transfemorais durante a contração isométrica em dinamômetro isocinético. Rev Bras Med Esporte. 2014;20 (5): 336-339. DOI: 10.1590/151786922014200501806 .

22. Hefferman GM, Zhang F, Nunnery MJ, Huang H. Integration of surface electromyographic sensors with the transfemoral amputee socket: A comparison of four differing configurations. Prosthet Orthot Int. 2015 Apr;39(2):166-73. doi: 10.1177/0309364613516484.

\section{Corresponding author}

Rafaella Carvalho da Silva University of Brasília, Faculdade de Ceilândia, Ceilândia Sul, Brasília DF, 72220-275

Email: rafaellacarvalhofisio@gmail.com

Manuscript received on April 25, 2019

Manuscript accepted on June 18, 2019

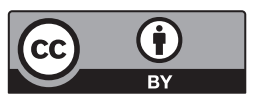

Motriz. The Journal of Physical Education. UNESP. Rio Claro, SP, Brazil - eISSN: 1980-6574 - under a license Creative Commons - Version 4.0 